\title{
Unexpected Undiagnosed Pheochromocytoma on Tahle: Anaesthetic Management
}

\section{JCR}

Puneet, SP Sharma, Kanchan Chauhan

Department of Anaesthesia and Critical Care, Sawai Mann Singh Hospital and Medical College, Jaipur, Rajasthan, India.

\section{Abstract:}

A 52 year male was admitted in a surgical ward with a large retroperitoneal mass. The patient underwent surgical intervention and the surgeon identified that the tumor was originating from the head of pancreas compressing major blood vessels. Markedly severe hemodynamic fluctuations occurred during the manipulation of the tumor which were managed with vasodilators and opioids. The tumor was successfully removed and patient was discharged without any sequelae after five days. The pathology report indicated a diagnosis of neuroendocrine tumor i.e pheochromocytoma. Unexplained pheochromocytoma may lead to fatal hypertensive crisis with a catastrophic sequelae during surgery.

Key words: Catecholamines, Hypertension, Nitroglycerin, Nitroprusside, Pheochromocytoma.

\section{Introduction}

Anaesthetic management of any surgical patient with pheochromocytoma is challenging, particularly when the tumor has not been diagnosed. Pheochromocytomas are catecholamines producing tumors derived from sympathetic or parasympathetic nervous system [1]. Uncontrolled catecholamines release can result in malignant hypertension, cerebrovascular accidents and myocardial infarction [2]. The incidence of pheochromocytoma is very low around, 2-6 patients per million per year with common age between 20-50 years and with female predominance. A proportion of patients are diagnosed at the time of incidental surgery and in this situation mortality rate is $80 \%$ [3]. The serious and potentially lethal nature of this hypertensive crisis is caused by the potent effect of the paroxysmal release of catecholamines. Thus they present a great challenge to the anaesthesiologist in the operating room as well in the intensive care unit.

\section{Case Report}

A 52 year old male patient presented with lower abdominal pain which was severe, spontaneous in onset, non-radiating, non-colicky since last two months. Patient was diagnosed to be suffering from a retroperitoneal lump and was posted for exploratory laparotomy for lump excision.

Corresponding Author: Dr. Puneet

Email: puneet.doc@gmail.com

Received: May 25, 2016 | Accepted: August 23, 2016 | Published Online: November 20, 2016

This is an Open Access article distributed under the terms of the Creative Commons Attribution License (creativecommons.org/licenses/by/3.0)

Conflict of interest: None declared | Source of funding: Nil | DOI: http://dx.doi.org/10.17659/01.2016.0132 
On physical examination, the height of the patient was $180 \mathrm{~cm}$, weight $84 \mathrm{~kg}$. The ASA score was grade 1 (healthy person) and Mallampati airway score was also 1. The patient had good mouth opening with a thyromental distance of more than $3 \mathrm{~cm}$, and the neck movements was normal. The patient was stable, conscious, cooperative and oriented to time place and person. On auscultation bilateral lungs were clear with normal heart sounds. The rest of the examination was unremarkable. ECG showed normal sinus rhythm.

Ultrasonography revealed $5.4 \times 4.2 \mathrm{~cm}$ rounded, well defined, hypo-echoic lesion with vascularity noted in epigastric region. PET scan revealed round, well defined, heterogenous enhancing soft tissue density space occupying lesion in the aortocaval region of the retero-peritoneum measuring approximately $50 \mathrm{~mm}$ diameter and closely abutting the head of pancreas and the second part of duodenum making the diagnosis of neoplastic mass with primary etiology [Fig.1].

Informed written consent was taken before surgery. In the operating room routine monitors were attached $\left(\mathrm{SpO}_{2}, \mathrm{NIBP}, \mathrm{ECG} \& \mathrm{EtCO}_{2}\right)$ and intravenous line secured. Pre-operative vitals were pulse: $86 / \mathrm{min}$, blood pressure: $126 / 82 \mathrm{~mm} \mathrm{Hg}$ with $98 \% \mathrm{SpO}_{2}$. Patient was premedicated with injection glycopyrrolate $0.2 \mathrm{mg}$, injection midazolam $1 \mathrm{mg}$, injectoin tramadol $100 \mathrm{mg}$ along with injection rantac $50 \mathrm{mg}$ and injection metaclopramide 10 mg. Preoxygenation was done with $100 \% \mathrm{O}_{2}$ for 3 minutes and patient was induced with injection propofol $100 \mathrm{mg}$, injection succinycholine $100 \mathrm{mg}$ and was intubated with $8.5 \mathrm{~mm}$ cuffed endotracheal tube. Anaesthesia was maintained with $\mathrm{O}_{2}+\mathrm{N}_{2} \mathrm{O}$ (40:60) and with injection atracurium $15 \mathrm{mg}$ loading dose then $5 \mathrm{mg}$ when required.

After opening the abdomen, bulging mass was found arising from the retroperitoneum. Tumor manipulation resulted in sudden rise of

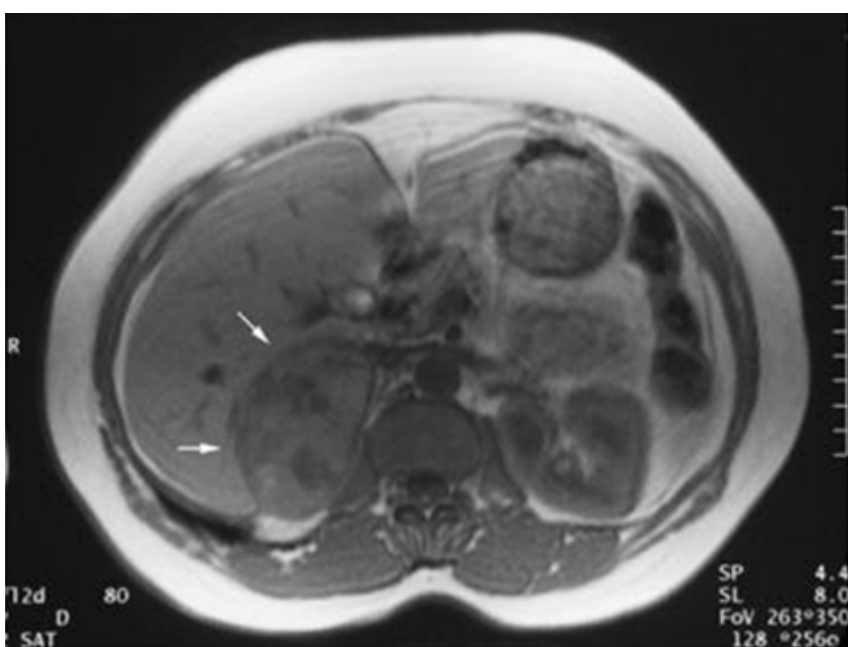

Fig.1: CT scan showing space occupying lesion closely abutting the pancreas and duodenum.

blood pressure to $306 / 183 \mathrm{~mm} \mathrm{Hg}$ and heart rate of $156 \mathrm{bpm}$ which was considered as monitor error. But similar readings were noted on manual recording. The depth of anesthesia was increased by administration of $100 \mu \mathrm{g}$ injection fentanyl but the reading was $280 / 166 \mathrm{~mm} \mathrm{Hg}$ with pulse rate of $160 \mathrm{bpm}$. Injection dexemedetomedine $50 \mu \mathrm{g}$ diluted in $10 \mathrm{~mL}$ normal saline was given over 5-10 minutes but still the BP remained high. So, injection nitroglycerin infusion was started at $0.5 \mu \mathrm{g} / \mathrm{kg} /$ $\mathrm{min}$, gradually dose was increased to $1 \mu \mathrm{g} / \mathrm{kg} / \mathrm{min}$ but nitroglycerin proved ineffective. Subsequently, blood pressure was effectively controlled with sodium nitroprusside (SNP) infusion at dosage of $0.5 \mu \mathrm{g} / \mathrm{kg} / \mathrm{min}$ titrated to $1.0 \mu \mathrm{g} / \mathrm{kg} / \mathrm{min}$ [Table 1]

Meanwhile the surgeon suspected the lump to be pheochromocytoma, clamped the suprarenal vein following which there was gradual fall in blood pressure to $130 / 96 \mathrm{~mm} \mathrm{Hg}$. The dosage of sodium nitroprusside injection was decreased to $0.5 \mu \mathrm{g} / \mathrm{kg} / \mathrm{min}$. Blood pressure of $116 / 76 \mathrm{~mm}$ $\mathrm{Hg}$ was achieved with pulse rate of $99 / \mathrm{min}$ and sodium nitroprusside was stopped [Fig.2]. As the fall in blood pressure continued, aggressive intravenous fluids were given to improve the left ventricular 
filling and blood pressure maintenance. Meanwhile the tumor mass was removed and was sent for histopathology [Fig.3]. At the end of surgery, patient was given $2.5 \mathrm{mg}$ injection neostigmine and $0.4 \mathrm{mg}$ injection glycopyrrolate and patient was extubated. Patient was shifted to ICU for strict vital monitoring. On post-operative day one, patient was completely asymptomatic and no sequelae was identified. The pathological report confirmed the diagnosis of paraganglioma - pheochromocytoma and the patient was discharged five days later without any complications.

\section{Discussion}

Pheochromocytoma is catecholamine producing tumor derived from sympathetic or parasympathetic nervous system. Clinical suspicion remains the single most important factor in the identification of pheochromocytoma. Generally patient presents with a widely fluctuating blood pressure, sweating and palpitations [4]. Preoperative management consists of control of blood pressure and restoration of intravascular volume [5]. Usually blood pressure is controlled with alpha adrenergic blockers over a period of 10-14 days. The drug of choice is phenoxybenzamine. Beta adrenergic blockers were added after effective alpha blockade.

In this case, the patient did not manifest any signs and symptoms suggestive of pheochromocytoma preoperatively like headache, palpitation or hypertension. A desensitization of cerebrovascular system or increased down regulation of adrenergic receptor may explain these findings [5]. We were unaware about the diagnosis preoperatively. The diagnosis was confirmed post-operatively by histopathology of the removed mass. Intraoperative hypertensive crisis during handling of the tumor was well managed by increasing the depth of anaesthesia, supplementation of opiods, nitroglycerine and sodium nitroprusside. Nitroglycerin and sodium
Table-1: Recorded haemodynamics during surgery and its management.

\begin{tabular}{|l|l|l|l|l|lr|}
\hline & $\begin{array}{l}\text { During } \\
\text { fumor } \\
\text { mani- } \\
\text { pulation }\end{array}$ & $\begin{array}{l}\text { After } \\
\text { inj.fentanyl } \\
(2 \mathrm{~min})\end{array}$ & $\begin{array}{l}\text { After } \\
\text { dexa- } \\
\text { metemedine } \\
(2 \mathrm{~min})\end{array}$ & $\begin{array}{l}\text { After } \\
\text { inj.nitoglycerin } \\
(2 \mathrm{~min})\end{array}$ & $\begin{array}{l}\text { After sodium } \\
\text { nitroprusside } \\
2 \text { min }\end{array}$ & $4 \mathrm{~min}$ \\
\hline Systolic $(\mathrm{mm} \mathrm{Hg})$ & 306 & 280 & 220 & 180 & 130 & 116 \\
\hline Diastolic $(\mathrm{mm} \mathrm{Hg})$ & 183 & 166 & 157 & 115 & 96 & 76 \\
\hline $\mathrm{SPO}_{2}(\%)$ & 100 & 100 & 100 & 99 & 99 & 99 \\
\hline Heart Rate (bpm) & 156 & 160 & 150 & 153 & 130 & 99 \\
\hline
\end{tabular}

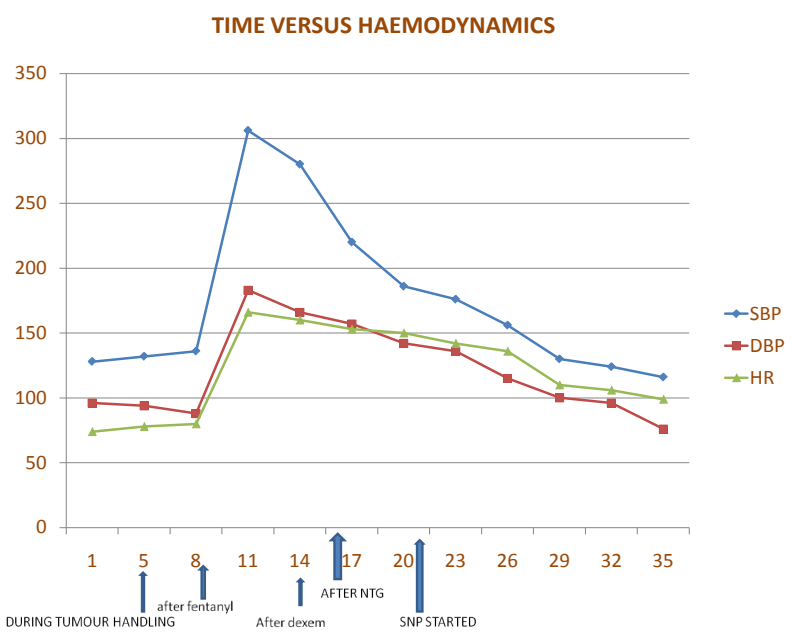

Fig.2: Graph showing time versus haemodynamics.

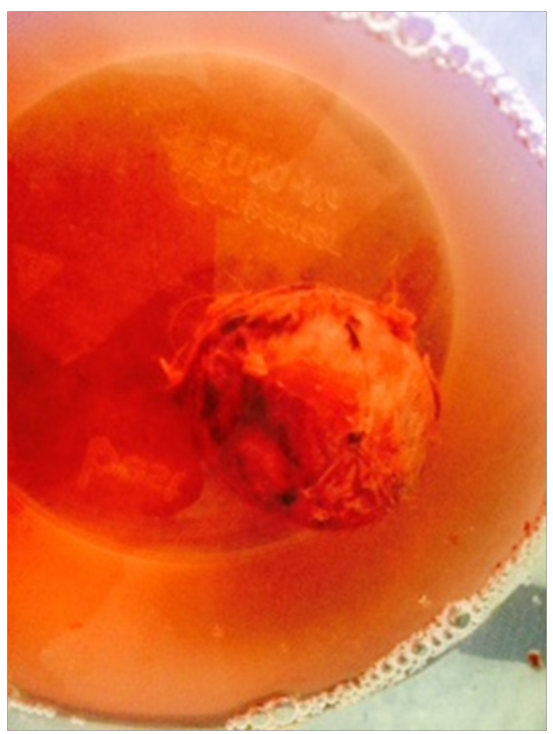

Fig.3: Tumor after resection. 
nitroprusside are potent vasodilators which help in controlling blood pressure.

Clamping the suprarenal vein causes sudden withdrawal of circulating catecholamine thus leading to sudden fall in the blood pressure which has to be managed with liberal intravenous fluids; replacement of blood loss and ionotropes i.e dopamine, dobutamine and noradrenaline. Postoperatively patients require intensive care monitoring with ionotropic support as they are highly vulnerable to hypertensive, hypotensive and hypoglycaemic episodes.

\section{Conclusion}

The management of pheochromocytoma remains a challenge for the anaesthesiologist despite of new landmarks in drugs and techniques. If unexpected hypertensive crisis is encountered during abdominal tumor surgery, undiagnosed pheochromocytoma should always be considered as a possibility.

\section{References}

1. Hull CJ. Pheochromocytoma: diagnosis, preoperative preparation and anaesthetic management. $\mathrm{Br} J$ Anaesth. 1986;58:14531468.

2. Hines RL, Marschall KE. In: Livingstone C (ed). Stoelting's anaesthesia and co- existing disease. 6th edition. India: Elsevier 2008. pp. 388-389.

3. Myklejord DJ. Undiagnosed pheochromocytoma: the anaesthesiologist nightmare. Clin Med Res. 2004;2:59-62.

4. Pyrs- Roberts C. Pheochromocytoma - recent progress in its management. $\mathrm{Br} J$ Anaesth. 2000:85:44-57.

5. Lertakyamanee $\mathrm{N}$, Lertakyamanee J, Somprakit P, Nimmanwudipong T, Buranakitjaroen $P$, Bhavakula $K$, et al. Surgery and anaesthesia for pheochromocytoma - a series of 40 operations. J Med Assoc Thai. 2000:83;921-927. 